\title{
De meninas tantas na escrita sensível de Adriana Falcão: reflexões sobre o feminino na literatura para a infância
}

\author{
Eliane Santana Dias Debus* \\ Camila Canali Doval \\ Fabiano Tadeu Grazioli****
}

\section{Resumo}

A literatura de recepção infantil pode estar em sintonia com os aspectos culturais da época em que é produzida. As obras Mania de explicação (2001), A Gaiola (2013a) e Valentina cabeça na Lua (2013b), de Adriana Falcão, se alinham com as características da literatura para crianças na atualidade e também constroem, no seu conjunto, um panorama da representação da personagem feminina infante na obra da autora. $\mathrm{O}$ artigo apresenta o processo de criação de Adriana Falcão em cada uma das obras listadas e faz uma abordagem do feminino em cada história, focalizando, principalmente, a construção da protagonista. Tal análise encontra respaldo em Michelle Perrot (2003), Regina Dalcastagnè (2012), Luiza Lobo [1997], Nancy Chodorow (2001), entre outros. O estudo aponta para uma nova perspectiva na construção das "meninas" nas obras literárias para crianças, que as coloca em condição de protagonizarem de fato suas histórias de vida e lidarem com suas emoções e sentimentos de modo a desvencilharem-se de estereótipos já conhecidos na vida real e na literatura infantil, colocando-as mais próximas da posição da mulher na sociedade contemporânea.

Palavras-chave: Adriana Falcão. Autoria feminina. Literatura para crianças. Feminino.

* Doutora em Linguística e Letras pela Pontifícia Universidade Católica do Rio Grande do Sul (PUCRS) e mestra em Literatura pela Universidade Federal de Santa Catarina (UFSC). Professora da Universidade Federal de Santa Catarina, atuando no Departamento de Metodologia de Ensino e no Programa de Pós-Graduação em Educação. E-mail: elianedebus@hotmail.com

* Doutora e mestra em Teoria da Literatura pela Pontifícia Universidade Católica do Rio Grande do Sul (PUCRS). Especialista em Estudos Linguísticos do Texto pela Universidade Federal do Rio Grande do Sul (UFRGS). Professora no Colégio La Salle Dores e no Colégio Concórdia, ambos em Porto Alegre. E-mail: cami.doval@gmail.com

**** Doutorando em Letras no Programa de Pós-Graduação em Letras, da Universidade de Passo Fundo (UPF). Mestre em Letras pelo mesmo programa. Professor do Departamento de Linguística, Letras e Artes, da Universidade Regional Integrada do Alto Uruguai e das Missões (URI), Campus de Erechim/RS, e da Faculdade Anglicana de Erechim (FAE).E-mail: tadeugraz@yahoo.com.br

Data de submissão: 07/07/2017 - Data de aceite: ago. 2017 http://dx.doi.org/10.5335/rdes.v13i2.7188 


\section{Introdução}

Para iniciarmos a construção deste texto, recolhemos de Adriana Falcão, em Mania de explicação, a definição de desculpa, que, segundo a personagem, "é uma frase que pretende ser um beijo" (FALCÃO, 2001); sintam-se beijados todos que nos leem. Num gesto desculpante, pedimos paciência se o discurso revelar-se demasiadamente fora do esperado. Mas afirmamos nossa alegria de adentrar por essa seara, sentindo no peito "um bloco de carnaval que não liga se não é fevereiro" (FALCÃO, 2001). Porque escrever sobre escrita do outro exige a coragem de desvelar-se na escrita.

$\mathrm{Na}$ esteira da literatura infantil e juvenil brasileira contemporânea, temos a possibilidade de escolha da autora sobre a qual gostaríamos de nos debruçar, e a opção, nesta ocasião, recaiu sobre a produção de Adriana Falcão, autora que viemos acompanhando a trajetória e que, no entanto, pouco temos nos debruçado sobre.

Na escolha do caminho de escrita, a indecisão, que é quando "você sabe muito bem o que quer, mas acha que devia querer outra coisa" (FALCÃO, 2001), tomou conta, pois tantas são as possibilidades de incursão, mas logo veio a certeza, já que em algum momento "a ideia cansa de procurar e para" (FALCÃO, 2001): nosso caminho será o de apresentar a autora focalizando alguns de seus livros para a infância que trazem o feminino. $\mathrm{O}$ percurso que traçamos para este trabalho apresenta inicialmente algumas questões sobre a trajetória de Adriana Falcão para depois adentrar no universo de três títulos para a infância em que o feminino se faz presente por meio da autoria, das personagens e dos paratextos, em particular das dedicatórias dos livros. No final do percurso, lançamos algumas palavras sobre a presença do feminino, partindo de estudos que olham para a produção da literatura de autoria feminina de modo a considerar sua recepção imprescindível desde a infância e que admitem que a literatura para a criança nasça com características ideologicamente reconhecíveis, pois, nas palavras de Anna Claudia Ramos, "o escritor cria a partir do seu olhar para o mundo e de como ele vê, sente e vive esse mundo" (2011, p. 32). As referências ao feminino compõem uma temática recorrente e reconhecível no conjunto de obras para a infância que Adriana Falcão publicou até o momento, pois suas obras revelam um olhar particular para o mundo, para as pessoas, para os acontecimentos.

Para trilhar o caminho proposto, apresentamos, neste artigo, estudo com características exploratório-descritivas e de abordagem qualitativa, e nosso procedimento técnico envolve pesquisa bibliográfica e documental, partindo de determinados conhecimentos já produzidos e explorando materiais que não receberam tratamento analítico específico. 


\section{Passarinhando no nome: as palavras de Adriana alçam voo}

Adriana Falcão, filha de Caio Franco de Abreu e Maria Augusta Teresa Izabel de Souza, nasceu no Rio de Janeiro, em 1960. Foi residir, aos 11 anos, em 1971, em Recife (Pernambuco), e foi pelas ruas dessa cidade, com os cabelos ao vento, como a menina (de) Clarice Lispector em Felicidade Clandestina, que "aprendeu o muito pouco que sabe” (FALCÃO, 2012). Lá se fez arquiteta; casou com o professor Tácio de Almeida Maciel; teve a filha Tatiana Maciel; descasou; recasou com o roteirista, diretor e compositor João Falcão. Com ele e com as filhas Maria Isabel e Clarice Falcão voltou para o Rio de Janeiro em 1995, onde começou a escrever para o cinema e a televisão e, em 1999, estreou na literatura.

Transitando por diferentes gêneros e espaços de escrita, sua produção se multiplica e ganha espaço no cenário brasileiro, fazendo parte da nossa geração de escritores contemporâneos, tais como os destacados por Andressa Fajardo:

Laura Bergallo, Fernando Bonassi, Mário Teixeira, Heloísa Prieto, Ivan Jaf, Menalton Braff, Gustavo Bernardo, Flávio Carneiro, Adriana Falcão, Caio Riter, Angélica Lopes, Jorge Miguel Marinho e Luís Dill (2014, p. 13).

Como roteirista colaborou com episódios de séries da Rede Globo, como $A$ comédia da vida privada (entre os anos de 1995 e 1997); Mulher (entre 1998 e 1999); A grande família (entre $2001 \mathrm{e}$
2014); já, entre seus trabalhos no cinema, destaca-se o Auto da compadecida (2000).

Na literatura, seu livro de estreia, $A$ máquina (2005), publicado pela primeira vez em 1999, recebeu de Luis Fernando Veríssimo as seguintes palavras:

A prosa de Adriana tem sortilégio. A gente se encanta com ela no sentido de se deliciar, mas também no sentido de cobra hipnotizada. De chegar ao fim e não saber bem o que aconteceu. Olha aí, outro talento surpreendente. De onde sai essa gente? Eu sei, eu sei. De Pernambuco (1999).

$\mathrm{Na}$ reedição de 2005, Mário Prata afirmou, na contracapa do livro, que "Essa menina mostra o Nordeste para o mundo, gargalhando de amor. Pintando a sua pequena aldeia, como diria Tolstói, tornou-se universal".

Segundo a escritora, sobre $A m a ́$ quina, sua pretensão era escrever uma peça teatral, porém o texto foi ganhando outra cara, seria uma crônica? Constituiu-se como romance publicado em livro (FALCÃO, 2012). Em 2000 foi adaptado para o teatro, entrou em cartaz em Recife, tendo no elenco Gustavo Lago, Lázaro Ramos, Vladimir Brichta, Wagner Moura e Felipe Koury e, em 2006, para o cinema, ambos adaptados por João Falcão. Esta produção mereceu interesse da pesquisadora Rivana Nogueira de Melo Couto em sua dissertação intitulada Linguagem literária e linguagem cinematográfica na obra A máquina, de Adriana Falcão, sob orientação de Maria Teresinha Martins do Nascimento, defendida na Universidade Federal de Goiás (UFG), em 2014. 
Ainda a partir de A máquina, Mônica Grisi e Roberto Seidel (2014) sintetizam o modo de Adriana Falcão tecer literatura em meio aos problemas que o país enfrenta, desde sua estreia:

[...] poderíamos sugerir que a escolha de Adriana Falcão expressa a sua forma de lidar, denunciar ou intervir nos problemas do país - objetivo que parece ser o pleito de uma ampla gama de escritores da nova safra, quando se propõem a focalizar as mazelas das favelas das grandes metrópoles, a violência desmedida que assola o cotidiano dos grandes centros ou, no caso de Falcão, a realidade opaca de um lugarejo que vive a eminência do seu fim (2014, p. 77).

A seguir elencamos outras produções de Adriana Falcão: Mania de explicação (2001); Histórias dos tempos de escola: memória e aprendizado (2002), que reúne textos com outros escritores; Luna Clara \& Apolo Onze (2002); O doido da garrafa (2003); Pequeno dicionário de palavras ao vento (2003); Contos de estimação (2003); A comédia dos anjos (2004); PS Beijei (2004); A tampa do céu (2005); Contos de escola (2005); O Zodíaco - Doze signos, doze histórias (2005); Sonho de uma noite de verão (Coleção Devorando Shakespeare) (2007); Sete histórias para contar (2008), finalista do Prêmio Jabuti, edição de 2009; A arte de virar a página (2009); O homem que só tinha certezas (2010); A gaiola (2013a); Valentina cabeça na Lua (2013b); Queria ver você feliz (2014).

Do conjunto dessa produção, destacamos especialmente a sua maestria com as palavras destinadas às crianças em três livros: Mania de explicação (2001),
A gaiola (2013a) e Valentina Cabeça na Lua (2013b). Publicados com o selo da Salamandra (Editora Moderna), os três títulos são encadernados em brochura, têm proximidade no tamanho e receberam cuidadosos projetos gráficos, com ilustradores de reconhecido trabalho.

\section{Uma menina com mania de explicação}

Mania de explicação, o primeiro livro de Adriana Falcão para infância, foi publicado em 2001, e, com ele, a autora recebeu o prêmio "O melhor para a criança”, da Fundação Nacional do Livro Infantil e Juvenil (FNLIJ), em 2002. Em abril de 2014, Mania de explicação ganhou versão para o teatro pela própria Adriana e por Luiz Estellita Lins, a pedido da atriz Luana Piovani, que estreou o espetáculo em abril de 2014, com direção, cenário e figurino de Gabriel Villela. Adaptando seu próprio texto para o palco, Adriana Falcão e seu parceiro no projeto foram premiados pela FNLIJ na categoria "Teatro" (2015).

O livro é dedicado a sua filha Maria Isabel, que lhe inspirou a criação da narrativa, quando a surpreendeu com a explicação de que sabia que o alimento coração de galinha assim é chamado porque é o coração de uma galinha. Diante da resposta de Adriana, "Claro, né, filha", a menina devolveu: "Claro que não, mãe, porque baba-de-moça não é a baba de uma moça" (FALCÃO, 2012). Adriana ficou surpresa com a resposta 
plausível, a filha explicava que nem tudo que parece é.

Nasce aí a menina com mania de explicação, personagem dadeira de ideias como a Emília, de Monteiro Lobato, que vai descomplicando "o mundo do lado de fora" ao inventar explicação para cada coisa e buscar com suas invencionices trazer boniteza a uma realidade tanta vezes inexplicável. Para ela, por exemplo, "solidão é uma ilha com saudade de barco" (FALCÃO, 2001, grifo nosso).

$\mathrm{Na}$ narrativa, a primeira explicação que a menina dá ao leitor é a da própria palavra explicação: "é uma frase que se acha mais importante do que a palavra" (FALCÃO, 2001). Ao criar, dessa forma, frases mais importantes do que as palavras, a menina liberta termos rotineiros de seus significados engessados, pois ela já sabe, e melhor do que a maioria dos adultos, que a vida não cabe em dicionários.

A história da menina na narrativa de Falcão é breve, o que contrasta com sua vontade imensa de explicar as coisas, os sentimentos, as sensações. $O$ narrador onisciente comunica, além do que já apontamos, que as pessoas implicavam com ela, afirmando que parecia filósofa, dada que era a tantas explicações. Diante de uma criança que filosofa, os adultos "disparam alarmes de carros bem no meio de seus peitos" (FALCÃO, 2001, grifo da autora), incapazes que são de aceitar uma nova perspectiva sobre suas definições já tão desgastadas, acostumadas, cansadas: "De tanto que a menina explicava, as pessoas às vezes se irritavam [....] e terminavam indo embora, deixando a menina lá, explicando sozinha" (FALCÃO, 2001). ${ }^{1}$ Maldade! Decerto adultos insensíveis, não acostumados com meninas inteligentes e faladeiras; adultos incapazes de perceber que as associações que a menina fazia eram, na verdade, poesia: um jeito sensível e revelador de construir explicações.

Assim, desassossegando as palavras e retirando-as de seu habitat natural, a autora brinca com a semântica vocabular introduzindo o impossível e o inesperado - a função comunicativa das palavras em outro estado de moradia, seguindo a vertente lúdica de José Paulo Paes (2011) no poema "Dicionário" - "Tombo: o que acorre entre o escorregão e o palavrão" (2011) -, do livro Poemas para brincar, que teve sua primeira edição em 1989. Algumas explicações da menina estão interligadas pelo encadeamento de palavras, que é quando a explicação recupera uma palavra da explicação anterior, como em: "Saudade é quando o momento tenta fugir da lembrança para acontecer de novo e não consegue" (FALCÃO, 2001, grifo nosso), que recupera a palavra "saudade" da definição de "solidão", transcrita anteriormente. A próxima explicação será a de "lembrança", palavra que foi utilizada para explicar "saudade": "Lembrança é quando, mesmo sem autorização, o seu pensamento reapresenta um capítulo" (FALCÃO, 2001, grifo nosso); explicação que, por sua vez, utilizou a palavra "autorização", a próxima a ser explicada: "Autorização é quando a coisa 
é tão importante que dizer 'eu deixo' é pouco" (FALCÃO, 2001, grifo nosso). É assim por mais algumas páginas e em diversos momentos da obra.

Outras explicações estão ordenadas pelo fato de as palavras pertencerem ao mesmo campo da experiência humana (digamos assim!), como as explicações de “decepção", "desilusão", "culpa” e "perdão". "Decepção: é quando você risca em algo ou em alguém um xis preto e vermelho" (FALCÃO, 2001). "Desilusão é quando anoitece em você contra a vontade do dia" (FALCÃO, 2001). "Culpa é quando você cisma que podia ter feito diferente, mas geralmente não podia" (FALCÃO, 2001). "Perdão é quando o Natal acontece em maio, por exemplo" (FALCÃO, 2001). Há uma temática comum que perpassa as palavras explicadas, ou melhor, as palavras são interligadas por pertencerem a um mesmo campo semântico, e assim, nesses momentos da narrativa, Adriana joga com sentidos de uma forma ou de outra, entrelaçando palavras com a seriedade de uma brincadeira de criança. Por essas observações, a construção de Mania de explicação não passa despercebida aos olhos e aos sentimentos do leitor atento.

Toda criança tem a fase dos porquês, elas enlouquecem seus pais com infinitas interrogações. A personagem de Mania de explicação não tem dúvidas, ela brinca de experimentar respostas, de criar significação; essa é sua forma de estar no mundo. Ela também não tem medo de saber, ao contrário, tem coragem de explicar até para os que não querem ou- vi-la, para os que preferem a ignorância ou o lugar-comum. Os adultos a deixam falando sozinha - afinal, ela não passa de uma criança, de uma menina, de uma menina com mania de explicação. Eles julgam brincadeira o que já é um ensaio para uma personalidade que não se acomoda nem se conforma. Será que mudarão de postura e a ouvirão quando for mulher feita e seguir bradando suas verdades aos quatro ventos? É provável que não, se considerarmos o que a longa história de discriminação contra as mulheres nos relata. Mas talvez, até a menina crescer, isso nem importe mais, porque - assim esperamos! - seu espaço no mundo já estará garantido, afinal, já foram grandes os passos dados pelas meninas e mulheres desde a "mocinha do século XIX", descrita por Michelle Perrot:

Assim se opera uma construção sociocultural da feminilidade, que Simone de Beauvoir analisou ( $O$ segundo sexo, 1949), feita de contenção, discrição, doçura, passividade, submissão (sempre dizer sim, jamais não), pudor, silêncio. Eis as virtudes cardeais da mulher. A educação deve inculcá-las nas meninas, pois é importante saber distinguir educação de instrução. Esta é o acesso ao saber: tem alguma utilidade? O século XIX responde que não para as meninas do povo e dá um sim reticente e bem dosado para as da alta sociedade. A educação, pelo contrário, que é a formação dos bons hábitos e produz boas esposas, mães e donas de casa, parece essencial. As virtudes femininas de submissão e silêncio, nos comportamentos e gestos cotidianos, são centrais nela. E, acima de tudo, o pudor, a honra feminina do fechamento e do silêncio do corpo. A mocinha, essa personagem criada pelo século XIX ocidental, devia ser pura como um lírio, muda em seu desejo (2003, p. 16). 
Nada mais distante da nossa personagem do que essa definição, mas a menina de Adriana Falcão não pretende ensinar os que não querem aprender, ou seja, adultos que se apegam à imagem da mocinha idealizada e se negam a enxergar as transformações urgentes pelas quais a sociedade vem enfim passando, mas antes estimular que as meninas de hoje não mais se intimidem como uma vez se intimidavam - ou eram intimidadas. Há não pouco tempo, elas não tinham o direito de saber; após muita luta e, como consequência dessa luta, a disseminação de representações femininas menos estereotipadas e mais emancipadas, as histórias estão sendo finalmente reescritas, e as velhas definições colocadas em aberto diante das intrépidas mocinhas do século XXI, para que elas possam participar ativamente de sua reconstrução. Das necessárias redefinições, a única que ainda desconcerta a menina de Mania de explicação é, não por acaso, como veremos, a do amor:
Amor
É um gostar
Que não diminui de
Um aniversário pro outro.
Não. Amor é um exagero...
Também não. É um desadoro...
Um batelada? Um exame, um
Dilúvio, um mundaréu, uma insanidade,
Um destempero, um despropósito, um
Descontrole, uma necessidade, um desapego?
(FALCÃO, 2001).

A explicação se faz impossível: "esse negócio de amor ela não sabia explicar, a menina" (FALCÃO, 2001). O amor, afinal, sempre foi cantado e contado pelos homens; às mulheres coube o papel de musa. A personagem, no entanto, quer descobrir de que se trata esse sentimento misterioso, e talvez sua hesitação se relacione com a novidade do protagonismo. É a vez de as mulheres definirem o amor, e sua perspectiva é certamente outra, da mesma forma imprescindível. E o amor com seus (des)cons(c)ertos é tema d'A gaiola, obra de Adriana Falcão em que mais uma personagem Menina, agora com "m" maiúsculo, se lança à busca de explicações que correspondam à sua vivência de tal sentimento.

\section{O amor com seus (des) cons(c)ertos}

A Gaiola (2013a), de Adriana Falcão, finalista do Prêmio Jabuti 2014, é dedicada a sua neta Isadora e nasce do desejo de explicar à menina um acontecimento muito particular: a sua separação de João Falcão, avô da menina. A ilustradora Simone Martins, utilizando-se da técnica de tinta acrílica sobre papel cartão, compõe, de forma magistral, as ilustrações que, quadro a quadro, dialogam com as palavras, escapulindo da mera função ilustrativa de dizer o já dito.

Em A gaiola, temos um narrador onisciente que apresenta o ponto de vista das duas personagens - a menina e o passarinho - pela duplicação do texto: ele "Era um passarinho que queria muito ser amado" (FALCÃO, 2013a, p. 04) e cai na varanda da casa de uma menina "que queria muito ser amada" (FALCÃO, 
2013a, p. 06) e que o encontra caído, exigindo cuidados. Nasce ali um amor incondicional e exclusivo, que chega a assustar o par romântico: "Os dois estavam assustados, mas também, quem não se assusta quando a porta do amor se abre e apresenta um mundo de possibilidades lá fora?" (FALCÃO, 2013a, p. 08).

Apegada a menina ao passarinho, apegado o passarinho à menina, era tanto amor e zelo que ele, curado completamente, não deseja se afastar, parece sentir medo de por algum impulso fazê-lo, e solicita uma gaiola. Gaiola que o aprisiona e, ao mesmo tempo, os mantém tão perto. Seria necessária atitude tão drástica?

E os dois pensaram juntos:

- Mas se um quer ser do outro,

Para que então a gaiola?

- Para garantir - concluíram (FALCÃO, 2013a, p. 17).

A relação amorosa entre a menina e a ave implume está segura, preso que está o amor. A possível descrição de um cárcere sofrível é diluída pela condição do aprisionamento em gaiola tão bonita, com "desenhos dourados", e pela fartura de alimento. No entanto, como destacado em texto anterior:

Os medos e as dúvidas nascem quando a menina percebe o passarinho admirando o belo dia além da gaiola, e ele, por sua vez, se assusta com o que o seu desejo pode provocar na menina. A privação se dá em mão dupla, pois ambas as personagens vivem o conflito de querer estar perto e ao mesmo tempo livre. O sentimento de posse que gera, no início, certo conforto, acaba por se esfacelar nas dúvidas, nos ciúmes, nas inseguranças da relação outrora tão equilibrada (DEBUS, 2015, p. 181-182).
Descobertos sentimentos tão díspares, ambos vão fingindo contentamento para não decepcionar o outro até que se indagam sobre a necessidade da gaiola e afastam-na. Libertos, descobrem-se ainda aprisionados, até que, em comum acordo, se despedem e criam asas. $\mathrm{O}$ final em aberto anuncia a possibilidade de novos encontros, não entre menina e passarinho, mas de outros quereres:

Esse é o final dessa história sem final.

Porque ela não acaba aqui.

Quando uma história chega ao fim, ela não abre infinitas

Possibilidades de recomeço? (FALCÃO, 2013a, p. 31).

A linguagem do livro é acessível, enlaçada por uma dimensão lírica, potencializada pelos elementos de encontro, entrega e despedida das personagens: a menina e o pássaro. Ave não antropomorfizada, simplesmente pássaro; passarinho sem distinção de espécie; de asas partidas. Menina, simplesmente mulher, sem substantivo próprio que a nomine. Narrativa de cunho realista, sem final feliz! A narrativa fratura, desse modo, o ideário tranquilizante e apaziguador das narrativas tradicionais, com seus finais fechados e suas personagens circunscritas ao "viveram felizes para sempre"; uma nova arquitetura é elaborada, proclamando a possibilidade de um novo recomeço. Recomeço ao qual o pássaro e a menina têm direito. Mas o final d' $A$ gaiola sinaliza questões que vão além da simples utilização de uma estrutura não tão comum nas narrativas para crianças. 
Era uma vez o tempo em que as meninas se contentavam com o impalpável - e intragável - viver-feliz-para-sempre; elas querem é viver feliz para ontem, à velocidade da sua luz. De preferência, com mais foco no viver do que no feliz, pois a literatura infantil tem desconstruído os finais sem graça, em que a felicidade coincide com o fim da ação, e privilegiado a estrada afora, em que acontecem todas as aventuras, se escondem todos os monstros, se descobrem todos os poderes. Ao contrário das princesas que esperavam - ou dormiam - boa parte das histórias, hoje menina nenhuma quer perder a parte da aventura, do desafio, que é sem dúvida a parte mais divertida. Conforme avalia Susana Funck, é justamente este o desafio da literatura contemporânea, o qual se aplica igualmente à literatura para crianças:

reconhecer e desestabilizar as representações de gênero, em especial as do feminino, que circulam sem qualquer questionamento no mais importante aparelho ideológico da contemporaneidade (2014, p. 30).

Questionar não é um problema para a Menina, principalmente sobre um dos maiores alicerces da cultura machista, $o$ amor romântico.

Enquanto grande parte da mídia, principalmente a televisiva, e também a indústria de blockbusters cinematográficos insistem nas narrativas tradicionais baseadas nos contos de fadas "versão Disney", em que a protagonista é construída sobre estereótipos de feminilidade, uma nova geração de escritoras, diretoras e protagonistas vem desconstruindo o status quo do binarismo entre os gêneros ao propor novas e diversificadas representações. O destaque para as mulheres, aqui, não se pretende "territorialista", apenas marcar que a própria expansão da autoria feminina nos mais diversos campos da cultura tem contribuído para esse retraçar do feminino, pois, como afirma Regina Dalcastagnè,

Muito além de estilos ou escolhas repertoriais, o que está em jogo é a possibilidade de dizer sobre si e sobre o mundo, de se fazer visível dentro dele (2012, p. 07).

Tal movimento adquire importância peculiar quando o assunto são as ficções produzidas para as crianças, em especial no campo da literatura, pois ampliam as possibilidades de reconhecimento entre personagem e leitoras ainda em formação. A heterogeneidade de atuação e a força das novas protagonistas potencializam, dessa forma, o caráter empático do gênero ao acolher outros desejos, sonhos e fantasias, aqueles fora de um mainstream conservador de expectativas da sociedade sobre as meninas.

A Menina de Adriana Falcão não chega a vestir a armadura do príncipe e sair à caça de dragões fogarentos, mas ousa voltar-se a seus próprios anseios em relação ao amor, anseios que não estão previstos nos contos de fadas:

Por que o Passarinho não podia gostar de outra coisa além dela? A Menina não queria ver seu amor, tão bonito, com cara de impedimento. $\mathrm{E}$, além de tudo isso, ela também achou o dia belo (FALCÃO, 2013a, p. 19).

Ela se sente confusa por deparar-se com um sentimento muito diferente da 
idealização que sempre fora ensinada às meninas. Onde estão as certezas? As premeditações? Os "para sempre"? Ela quer o Passarinho, mas ela também quer o mundo. E acha injusto que o Passarinho não possa mais sentir desejo por esse mesmo mundo tão atraente apenas porque a encontrou. Ela então apela "Ai, ai, ai, e agora?, meu Deus, minha Nossa Senhora, o que é que se faz com os medos?" (FALCÃO, 2013a, p. 20) - e aprende, com sua primeira experiência no amor, que não há como se livrar das inseguranças, mas é possível descomplicá-las e vivê-las como parte do processo de amar(-se), relacionar-se, construir-se, tudo isso de igual para igual com o ser amado.

Um pouco mais adiantada no processo de desvencilhar-se de amarras conservadoras está Valentina, que já tem nome e concepções próprios, embora, para muitos, a "cabeça na lua" ainda provoque apreensão.

\section{Com a cabeça na Lua: Valentina}

Diferentemente das outras duas narrativas em que as meninas não são substantivadas com nominação própria, em Valentina cabeça na Lua (2013b), o nome da protagonista se destaca já no título. E, talvez para o leitor acostumado a relacionar os nomes das personagens à sua personalidade nas histórias, o nome represente "valentia", "a valente", pois para assumir determinados jeitos de ser, que não correspondem sempre ao que o adulto espera da criança, ela precisa de uma centelha de valentia. Para viver no mundo da Lua quando pais, mães, professores (os adultos em geral) a querem com os pés e a cabeça no chão, haja valentia! O livro é dedicado a uma Valentina e sua Lua, que, nas palavras de Adriana na dedicatória, "estão cheias de estrelas em volta” (FALCÃO, 2013b, p. 03).

Se, em Mania de explicação, a personagem principal gosta de explicar poeticamente o significado das coisas, Valentina é mais dada às perguntas: e não lhe incomodavam as perguntas sem respostas, pois "eram aquelas que nasciam dentro da gente, num lugar sem tempo nem espaço" (FALCÃO, 2013b, p. 10) e ainda "eram perguntas de verdade. Perguntas, perguntas. Dessas que a gente fica horas pensando na pergunta e não na resposta" (FALCÃO, 2013b, p. 11). Mas Valentina também gostava de um monte de outras coisas no mundo, daquilo que as outras crianças gostam (ou melhor, quase todas as outras crianças gostam):

[...] estrela da noite, música bonita, história de filme, amigo de verdade, cheiro de livro novo, brincadeira maluca, colo de mãe, passeio de domingo, celular que tem joguinho, dia enfeitado de arco-íris, resto de orvalho na planta, vitrine colorida, peixinho dourado, gota de chuva escorrendo na janela, lápis de cor verde piscina, hora do recreio, gelatina balançando, boneco que ascende no escuro, cachorrinho que nasceu, surpresa de ovo de páscoa, vento na cara (FALCÃO, 2013b, p. 04). 
O narrador onisciente comunica ao leitor, já no início da história, esses gostares todos de Valentina. Eles universalizam a menina (quem não gosta, por exemplo, de colo de mãe?), mas também a particularizam (nem toda criança precisa gostar da cor verde piscina, não é?). Mas acontece que ela gostava de tanta coisa, que não dava para pensar em tudo ao mesmo tempo, "se não ia ficar tudo embolado: estreladanoitemúsicabonitahistóriadefilmeami [...]" (FALCÃO, 2013b, p. 05). $\mathrm{O}$ recurso criativo de embolar as letras traduz visualmente a bagunça em que ficariam aqueles pensamentos todos juntos na cabeça de Valentina. Por isso mesmo, ela pensava uma coisa de cada vez. Resultado disso: ela estava sempre pensando. Resultado (um pouco) chato disso: diziam que ela tinha a cabeça na Lua.

Mas o narrador, conhecedor das minúcias da história, afirma que "A Lua não saía da cabeça de Valentina" (FALCÃO, 2013b, p. 07) e traz uma explicação-chave para o leitor compreender o modo de a menina organizar os seus pensamentos e, consequentemente, o seu mundo interior:

Porque na cabeça de Valentina, tudo está arrumado assim: cada coisa que existia de verdade morava no lugar de cada coisa. Mas tudo que existia só na sua cabeça, morava na Lua. Para ela, a Lua é o lugar onde vivem os melhores pensamentos das pessoas e as respostas das perguntas sem resposta (FALCÃO, 2013b, p. 08).

A Lua é um lugar muito especial para a nossa menina das perguntas. $\mathrm{O}$ fato de a palavra ser grafada com inicial maiúscula (uma coincidência da Língua Portuguesa) endossa ainda mais o status de personagem que o satélite natural da terra tem na história. A Lua é percebida como companheira e cúmplice por Valentina.

A essa altura da história é quase desnecessário o narrador informar-nos que uma das coisas que a menina mais gosta é de fazer perguntas. Mas desnecessário não é informar que "[...], Valentina adorava pergunta de criança" (FALCÃO, 2013b, p. 13). É que pergunta de adulto, assim como a maioria das crianças, Valentina e o narrador (que chama o leitor para trocar uma confidência: "cá entre nós") acham chata ou então muito sem graça.

Talvez pergunta de adulto seja assim tão besta porque tem resposta certa, pensava Valentina. [...]. Não dá para ficar ligada em coisas pequenas, quando tem tantas perguntas importantes por aí, abarrotando a cabeça da gente (FALCÃO, 2013b, p. 17).

É este o pensamento de Valentina, o mundo que construiu para si não tem espaços para a pequenez dos adultos, e Adriana Falcão simbolizou essa tendência aos assuntos mundanos e triviais nas perguntas que os adultos fazem. Essa falta de correspondência entre as perguntas que interessam aos adultos e as que interessam à Valentina faz com que a menina deixe de compartilhar com a mãe um momento ímpar da historia, que poderia ser de troca, ternura e afeto. A menina indaga-se sobre um momento de pura poesia, que sempre intrigou as crianças, despertando-lhes as mais diversas emoções: 
"Como será o nome disso que a gente sente quando vê uma estrela cadente caindo?"

Emoção?

Esperança?

Encantamento?

Olha só que sorte a minha? (FALCÃO, 2013b, p. 18-19).

Quando a mãe chega ao sótão, questionando de modo ríspido se Valentina "está com a cabeça na Lua" (FALCÃO, 2013b, p. 21), a menina disfarça seu fascínio e sua empolgação pelo que acabou de ver e cede ao mundo adulto dizendo para a mãe que estava pensando em uma conta (cinco vezes nove!), quando, na verdade, no seu íntimo, brota a seguinte resposta, a que ela realmente gostaria de ter dado: "- Claro que estou, não é, mamãe, pois preciso encontrar a resposta de uma pergunta importantíssima: como é o nome disso que a gente sente quando vê uma estrela cadente caindo?" (FALCÃO, 2013b, p. 22). Diante da (falsa) resposta, a mãe lhe devolve a mesma pergunta sobre a tabuada, só para ter certeza de que a menina estava pensando na conta. É o momento em que Valentina responde, para alívio da mãe, o resultado correto. $O$ narrador não desperdiça a crítica: "Que mãe não ficaria orgulhosa de saber que sua filha é menina ajuizada, sensata, instruída, estudiosa e ainda é boa em tabuada" (FALCÃO, 2013b, p. 26).

Aos olhos da mãe, Valentina possui as qualidades listadas pelo narrador, o único "problema" é que vive com a cabeça no mundo da Lua. Para Valentina, as qualidades elencadas são secundárias, a ela importa mesmo o seu mundo interior, suas perguntas sem respostas (ou que deixam os adultos sem respostas), que a colocam em contato com os aspectos enlevados, contemplativos e meditativos representados pela Lua. E é com a cabeça na Lua, depois de aquietar o coração da mãe, que Valentina termina a história:

"Como seria o nome daquilo que a gente sentiria se visse quarenta e cinco estrelas cadentes caindo todas elas ao mesmo tempo?" $\mathrm{E}$ a Lua ficou cheia, cheia de alegria e amor-próprio.

É que a Lua adora esse tipo de pergunta (FALCÃO, 2013b, p. 28-29, grifo da autora).

As ilustrações de Alexandre Rampazo colocam Valentina e a Lua em evidência. A concepção da vestimenta da menina lembra uma camisola de mangas longas, de cor vermelha. Acerto do ilustrador, já que o projeto ilustrativo (e não exatamente o texto) coloca a menina em cenas noturnas e sempre com essa mesma roupa. A camisola de Valentina lembra o místico, o transcendente, o cabalístico, principalmente na imagem da capa, que é a reprodução das páginas 30 e 31, que encerram a história: Valentina, vestida de vermelho e erguida por balões azuis, flutua em direção à imensa Lua que a atrai lá do céu. Há um forte apontamento, nessa imagem, à consagrada relação entre a Lua e o feminino - não por acaso o ciclo menstrual é também chamado de ciclo lunar pessoal. A relação de Valentina com a Lua remete ao que as mulheres carregam de natureza e também de sonho, liberdade e capacidade de se desfazer e refazer nas fases tão bem 
descritas por Cecília Meireles em seu poema "Lua adversa": "Fases que vão e que vêm,/ no secreto calendário/ que um astrólogo arbitrário/ inventou para meu uso" (MEIRELES, 1976, p. 193-194).

A Lua, assim como rege as marés, rege os pensamentos importantes de Valentina e atrai-os a crescerem e voarem dentro e para fora da menina. De outro lado, a mãe de Valentina representa a força contrária e tenta afastar a filha da influência lunar, para que a menina plante de vez seus pés na segurança da Terra. A luta se dá, assim, entre os valores da mãe - que Valentina seja sensata e instruída, características valorizadas pelas sociedades regidas pela racionalidade masculina - e os da Lua - que admira as meninas sonhadoras e curiosas, aspectos associados, culturalmente e de forma pejorativa, às mulheres. O comportamento da mãe, que desperta determinada reação na filha, é bem retratado por Nancy Chodorow em Psicanálise da maternidade:

As mães se sentem ambivalentes em relação a suas filhas e reagem à ambivalência de suas filhas para com elas. Elas desejam ao mesmo tempo mantê-las perto de si e impeli-las à idade adulta. Essa ambivalência por sua vez causa mais ansiedade em suas filhas e provoca esforços dessas filhas no sentido de libertar-se (2001, p. 172).

Sobre o embate entre a mãe e a Lua é importante observar que, ainda na ilustração mencionada, o elemento inusitado são os balões azuis a carregar a menina, cuja leveza e efemeridade parecem relembrar tanto à mãe quanto à Lua que Valentina, apesar da maturidade, é uma criança e, como tal, tem direito às suas próprias experiências, seus próprios caminhos e, principalmente, seu próprio tempo.

As ilustrações de Valentina cabeça na Lua são um belo exemplo da importância da ilustração e da sua capacidade de contar histórias dentro de histórias: acrescentam ao texto elementos que não são citados na literatura de Adriana Falcão, no máximo existem nas suas entrelinhas. É preciso maestria para "pinçar" esses elementos e inseri-los na materialidade da página, sem, no entanto, interferir na história principal, pelo contrário, por um lado, respeitando seus limites e, por outro lado, enriquecendo-a.

\section{Para o fechamento: o feminino nas obras analisadas}

De estilo peculiar, as três narrativas se constroem estruturalmente por meio de frases curtas e ligeiras, carregadas de dinamismo. São de linguagem acessível sem ser fácil, pois são encharcadas de poeticidade, enlaçadas por uma dimensão lírica. Narrativas de cunho realista, em que os percursos das personagens, como destaca Ramos, "São feitos pela via da introspecção, com a valorização do olhar, dos afetos, dos universos familiares e das vivências quotidianas" (2012, p. 35). Constata-se a presença reiterada das personagens femininas meninas que estão em processo de descobertas: a me- 
nina que tudo quer explicar, de Mania de explicação; a Menina que não sabe 0 que fazer com $o$ amor aprisionado, de $A$ gaiola; e a menina que se conecta com a Lua e seu universo por meio das perguntas sem respostas que carrega dentro de si, de Valentina cabeça na Lua.

É muito importante destacar essa reiteração do feminino tanto no espaço reservado ao protagonismo das três personagens quanto na autoria de Adriana Falcão. Importante porque a trajetória da autoria feminina é que abriu espaço para a desconstrução de estereótipos, como o da "mocinha", e para o estabelecimento de novos laços entre a mulher e a sua representação, que outrora era regida pelo olhar masculino. Luiza Lobo [1997] assim explica esse processo:

Do ponto de vista teórico, a literatura de autoria feminina precisa criar, politicamente, um espaço próprio dentro do universo da literatura mundial mais ampla, em que a mulher expresse a sua sensibilidade a partir de um ponto de vista e de um sujeito de representação próprios, que sempre constituem um olhar da diferença. A temática que daí surge será tanto mais afetiva, delicada, sutil, reservada, frágil ou doméstica quanto retratará as vivências da mulher no seu dia a dia, se for esta sua vivência. Mas o cânone da literatura de autoria feminina se modificará muito se a mulher retratar vivências resultantes não de reclusão ou repressão, mas sim a partir de uma vida de sua livre escolha [...] ([1997]).

É muito bonito observar que a literatura para crianças venha desenvolvendo esse projeto com maestria, ao apresentar personagens tão determinadas a viverem suas escolhas, como as três meninas de
Adriana Falcão, abrindo, assim, novas possibilidades de representação para as pequenas leitoras e contribuindo para o desenvolvimento da sensibilidade nos meninos em relação à posição da mulher na sociedade contemporânea. A quebra dos estereótipos de feminilidade e também de masculinidade nas representações, desde os primeiros enredos literários, propicia a instauração de um novo olhar para ambos, meninos e meninas, futuros cidadãos aos quais em breve caberá a não simples tarefa de fazer desse mundo um lugar mais justo para todos e todas.

\section{Reflections about the female figure in the children's literature, focusing on Adriana Falcão's sensitive writing of many girls}

\section{Abstract}

The children's reception literature may be connected to the cultural aspects of the era in which it is produced. The following works Mania de explicação (2001), A Gaiola (2013a) and Valentina cabeça na Lua (2013b), written by Adriana Falcão, are linked to the present characteristics of the children's literature. Furthermore, these stories build a panorama of the representation of the female infant character in the author's work. The article presents Adriana Falcão's creation process of each work. Furthermore, it approaches the female figure in each story, focusing on the construction of the protagonist. This analysis is based on Michel- 
le Perrot (2003) Regina Dalcastagnè (2012), Luiza Lobo [1997], Nancy Chodorow (2001), among others. This study points to a new perspective of the girls' construction in the literary works for children. So, the female characters play the protagonist role in their stories in which they deal with their emotions and feelings. So, these girls are put in this position in order to get rid of the stereotypes which the women are already known in the real life and in the children's literature. Thus, they are placed closer to the women of the contemporary society.

Keywords: Adriana Falcão. Children's Literature. Female. Female authorship.

\section{Notas}

1 Embora Adriana Falcão não use travessão para cada explicação, é como se a menina se pronunciasse a cada palavra explicada, assumindo na narrativa o discurso direto. Poucas são as oportunidades em que o narrador se pronuncia, comparadas com as vezes em que a menina toma as rédeas do discurso com as suas explicações.

\section{Referências}

CHODOROW, Nancy. Psicanálise da maternidade: uma crítica a Freud a partir da

mulher. São Paulo: Rosa dos Tempos, 2001.

DALCASTAGNÈ, Regina. Literatura brasileira contemporânea: um território contestado. Vinhedo: Horizonte/Rio de Janeiro: Editora da UERJ, 2012.

DEBUS, Eliane. Revoar de passarinhos na literatura para a infância: um discurso de bem querer. In: BRAGA, Elda Firmo; LIBANORI, Evely Vânia; DIOGO, Rita de Cássia
M. (Org.). Representação animal na literatura. Rio de Janeiro: Oficina da Leitura, 2015.

FAJARDO, Andressa. Luís Dill e a narrativa para jovens: o gênero policial. 2014. $178 \mathrm{f}$. Dissertação (Mestrado em Letras) - Universidade Estadual de Maringá, Maringá, 2014.

FALCÃO, Adriana. A arte de virar a página. Rio de Janeiro: Objetiva, 2009.

. A comédia dos anjos. São Paulo:

Editora do Brasil, 2004.

. A máquina. Rio de Janeiro: Objetiva, [1999] 2005.

. A tampa do céu. São Paulo: Salamadra, 2005.

A gaiola. Ilustrações de Simone Matias. São Paulo: Salamandra, 2013a.

. Contos de estimação. Rio de Janeiro: Objetiva, 2003.

. Luna Clara e Apolo Onze. São Paulo: Moderna, 2002.

Mania de explicação. Ilustrações de Mariana Massarani. São Paulo: Salamandra, 2001.

O doido da garrafa. São Paulo: Planeta do Brasil, 2003.

O homem que só tinha certezas. São Paulo: Planeta do Brasil, 2010.

O Zodíaco: doze signos, doze histórias. São Paulo: Nova Alexandria, 2005.

- Pequeno dicionário de palavras ao vento. Projeto gráfico e ilustrações José Carlos Lollo. São Paulo: Editora Planeta do Brasil, 2003.

. Queria ver você feliz. Rio de Janeiro: Intrínseca, 2014

Sete histórias para contar. Ilustrações de Ana Terra. Sâo Paulo: Moderna, 2008.

Sonho de uma noite de verão. Rio de Janeiro: Objetiva, 2007. 
. Uma conversa com Adriana Falcão. III Mostra SESC de Literatura contemporânea, Santa Rita, Recife, 2012. Disponível em: <https://www.youtube.com/watch?v=DOA07thKE-w.>. Acesso em: 02 jun. 2017.

- Valentina cabeça na Lua. Ilustrações de Alexandre Rampazo. São Paulo: Salamandra, 2013b.

FALCÃO, Adriana et al. Contos de escola. São Paulo: Nova Alexandria, 2005.

FALCÃO, Adriana et al. Histórias dos tempos de escola: memórias e aprendizado. São Paulo: Nova Alexandria, 2002.

FALCÃO, Adriana; VERÍSSIMO, Mariana. P. S. beijei. Ilustrações de José Carlos Lollo. São Paulo: Salamandra, 2004.

FUNCK, Susana Bornéo. Desafios atuais do feminismo. In: STEVENS, Cristina; OLIVEIRA, Susane Rodrigues de; ZANELLO, Valeska (Org.). Estudos feministas e de gênero: articulações e perspectivas. Ilha de Santa Catarina: Editora Mulheres, 2014. p. 22-35. Disponível em: <http://media.wix.com/ugd/2ee9da_e10f81157da84b8f881635643ba9400d. pdf>. Acesso em: 12 jun. 2017.

GRISI, Mônica; SEIDEL, Roberto Henrique. Símbolos de nordeste no romance A máquina, de Adriana Falcão. Sociopoética. Campina Grande, v. 1, n. 12, p. 71-101, jan./jun. 2014. Disponível em: <revista.uepb.edu.br/index. php/sociopoetica/article/download/.../14>. Acesso em: 06 jun. 2017.

LOBO, Luiza. A literatura de autoria feminina na América Latina. Revista Brasil de Literatura, Rio de Janeiro, Ano I, julho-setembro 1997. [1997]. Disponível em: <http:// lfilipe.tripod.com/LLobo.html>. Acesso em: 08 jun. 2017

MEIRELES, Cecília. Viagem/Vaga Música. Rio de Janeiro: Civilização Brasileira, 1976.

PAES, José Paulo. Pomas para brincar. 17. ed. Ilustrações de Luiz Maia. São Paulo: Ática, 2011.
PERROT, Michelle. Os silêncios do corpo da mulher. In: MATOS, Maria Izilda; SOIHET, Rachel (Org.). O corpo feminino em debate. São Paulo: Editora UNESP, 2003. p. 13-27.

PRATA, Mário. Contracapa. In: FALCÃO, Adriana. A máquina. Rio de Janeiro: Objetiva, [1999] 2005.

RAMOS, Anna Claudia. Livros, leituras, escrituras... In: BOCHECO, Eloí Elisabete; GRAZIOLI, Fabiano Tadeu; DURLI, Zenilde. Um dedo de prosa, outro de poesia: conversas com quem gosta da palavra. Erechim: Habilis, 2011.

. Tendências contemporâneas da literatura portuguesa para infância e juventude. Porto: Tropelias \& Companhia, 2012.

VERÍSSIMO, Luís Fernando. Apresentação. In: FALCÃO, Adriana. A máquina. Rio de Janeiro: Objetiva, 1999. 